\title{
Phylogenetic characterization of a microsporidium (Nosema sp.) isolated from the mulberry pest, Hemerophila atrilineata
}

\author{
Rui Guan ${ }^{1}$, Zhongyuan Shen ${ }^{1,2,3}$, Feng Zhu ${ }^{1}$, Darui Chen ${ }^{1}$, Jiao Zhang ${ }^{1}$, Jiange Hou ${ }^{1}$, Shinan Dong ${ }^{1}$, Xudong \\ Tang $^{1,2}$ and $\mathbf{L i ~ X \mathbf { u } ^ { 1 , 2 }}$
}

\author{
${ }^{1}$ Jiangsu University of Science and Technology, Zhenjiang 212018, Jiangsu Province, China; \\ ${ }^{2}$ Sericultural Research Institute, Chinese Academy of Agricultural Sciences, Zhenjiang 212018, Jiangsu Province, China; \\ ${ }^{3}$ Key Laboratory of Genetic Improvement of Silkworm and Mulberry of Agricultural Ministry, Zhenjiang 212018, Jiangsu \\ Province, China
}

\begin{abstract}
Microsporidia are a group of obligate intracellular unicellular eukaryotes that can parasitize a wide variety of other eukaryotes ranging from protists to invertebrates and vertebrates. In this study, we examined the microsporidium Nosema sp. isolated from the mulberry pest, Hemerophila atrilineata Butler, 1881, named herein "Nosema sp. HA". The fresh spores were long oval in shape, $3.8 \pm 0.4 \mu \mathrm{m}$ in length and $1.9 \pm 0.3 \mu \mathrm{m}$ in width. Analysis of tissue infection of silkworm, Bombyx mori Linnaeus, 1758 , indicated that the midgut, Malpighian tubules, muscle, fat body, silk glands, hemocytes, nerve tissue and gonads of silkworm were infected with Nosema sp. HA. The complete rRNA gene sequence of this microsporidium contained 4305 base pairs (GenBank Accession JN882299), including the large subunit rRNA (2492 bp), the internal transcribed spacer (187 bp), the small subunit rRNA (1232 bp), the intergenic spacer (279 bp) and the 5S region (115 bp). The organization of the rRNA gene is 5'-LSU-ITS-SSU-IGS5S-3'. Phylogenetic analysis, comparison of sequence identities and the arrangement in the rRNA gene subunits suggested that this isolate is separate from other Nosema species.
\end{abstract}

Keywords: Nosema sp. HA, gene organization, microsporidium, rRNA gene, phylogenetic analysis

This article contains supporting information (Tables S1-S3) online at http://folia.paru.cas.cz/suppl/2012-59-2-87.pdf

Microsporidia are obligate intracellular parasites and the phylum consists of approximately 160 genera and over 1300 species (Corradi et al. 2009). Although microsporidia were previously regarded as primitive eukaryotes, they are now widely accepted as belonging to the kingdom Fungi (James et al. 2006). Since the first discovery in the 1850 's, microsporidia have been identified as causative agents of microsporidioses, which have been found in many vertebrates and invertebrates, including insects, fishes, and human beings (Sprague 1977, Canning et al. 1986, Wittner and Weiss 1999, Wasson and Peper 2000, Franzen and Muller 2001). Microsporidia also cause serious problems in fisheries and sericulture, especially during breeding and cocoon production (Liu et al. 2011).

Insects, especially the Lepidoptera and Hymenoptera, are frequently considered as the primary hosts for microsporidia (Sprague 1977, Schuld et al. 1999, Tsai et al. 2003). Several microsporidian genera such as Nosema, Pleistophora, Thelohania, Vairimorpha and Endoreticulatus have been found to infect the silkworm, Bombyx mori Linnaeus, 1758 (Bhat et al. 2009). They may infect fat body, nervous system, reproductive organs, muscles, silk glands and Malpighian tubules, and can cause systemic infection (Solter and Becnel 2000, Johny et al. 2006).

In our earlier study, Dong et al. (2010) have analysed information from SSU rRNA sequences of Nosema sp. from the mulberry pest, Hemerophila atrilineata Butler, 1881. They named it as "Nosema sp. HA" and placed it tentatively to the genus Nosema Nägeli, 1857. In this paper, in order to provide more biological information about Nosema sp. HA, we further confirmed its taxonomic status by describing its morphology in tissues of the silkworm and phylogenetic relationships inferred from sequence identities and the arrangement of the rRNA gene subunits.

\section{MATERIALS AND METHODS}

\section{Microsporidian isolate}

Spores were isolated from Hemerophila atrilineata collected from the mulberry field, and preserved at the Pathology Department of the Sericulture Research Institute of the Chinese Academy of Agricultural Sciences. Purification of Nosema sp. HA was done as previously described (Zhu et al. 2011) and is briefly 
summarised herein. The infected H. atrilineata larvae were homogenized with sterile water, the homogenates were filtered through four layers of cheesecloth, then centrifuged at $3000 \mathrm{~g}$ for $15 \mathrm{~min}$. The pellets were purified by $90 \%$ Percoll gradient centrifugation at $15000 \mathrm{~g}$ for $40 \mathrm{~min}$. A white band close to the bottom of the centrifuge tube was collected and washed several times with sterile water. The purified spores were stored at $4{ }^{\circ} \mathrm{C}$ for further use. Spore size was measured and photographed under a light microscope (IL/Leica Microsystems, Inc., Deerfield, MA, USA).

\section{Transmission electron microscopy}

Purified spores of Nosema sp. HA were fixed in $2.5 \%$ glutaraldehyde in $0.1 \mathrm{M}$ cacodylate buffer ( $\mathrm{pH} 7.4$ ) overnight. Samples were postfixed in 1\% osmium tetroxide for two hours, dehydrated through ascending ethanol series, and embedded in Epon-Araldite. Ultrathin sections were cut with Reichart-Jung ULTRACUT E ultramicrotome, stained in methanolic uranyl acetate and then lead citrate. Stained grids were observed using a JEM-1230 (JEOL, Japan) transmission electron microscope.

\section{Tissue infection}

Silkworm larvae were fed on Nosema sp. HA by smearing the spore suspension on the mulberry leaves and raised in routine conditions. All tissues from the infected larvae were rinsed several times with distilled water to prevent possible contamination and then examined for the presence of spores using light microscope.

\section{DNA extraction, amplification and sequencing}

Genomic DNA was extracted from the microsporidian spores as described previously by Dong et al. (2010). The primers used for the large subunit (LSU) rRNA gene amplification were LSUF/LSR and LSF/ILSUR (Zhu et al. 2010). We amplified the coding region of the small subunit (SSU) rRNA gene using the primer set $18 \mathrm{f}$ and $1537 \mathrm{r}$; the primers used for the internal transcribed spacer (ITS) gene amplification were ILSUF/S33R (Huang et al. 2004). The intergenic spacer (IGS) gene and the $5 \mathrm{~S}$ region amplification were amplified by ISSUF (Zhu et al. 2010) and 5SR (Huang et al. 2004). PCR amplification was carried out according to Zhu et al. (2010). Sequences were submitted to GenBank (Accession No. JN882299).

\section{Data analysis}

LSU rRNA and SSU rRNA nucleotide sequences of Nosema sp. HA were aligned with homologous rRNA gene sequences of 15 microsporidia from the NCBI GenBank database using CLUSTAL X version 1.83 and Schizosaccharomyces pombe as an outgroup. Phylogenetic tree was constructed with nucleotide sequences using molecular evolutionary genetic analysis (MEGA 4.0) (Tamura et al. 2007). One thousand bootstrap replications were performed to test the robustness of the estimated phylogenetic trees. Subsequently, the length and GC content of the rRNA genes were analysed with the Editseq program of DNAstar software package (DNASTAR, Madison, WI, USA) and identity and pairwise distance of the sequences of selected microsporidian species were analysed using Megalign program (DNAStar).

\section{RESULTS}

\section{Morphological characteristics}

Light microscopy revealed that the spores of fresh Nosema sp. HA were long oval in shape with a length of $3.8 \pm 0.4 \mu \mathrm{m}$ and a width of $1.9 \pm 0.3 \mu \mathrm{m}$. Transmission electron microscopical observations of sections of mature spores revealed that the spore wall consisted of an electron-dense exospore and electronlucent endospore layer and that the sporoplasm was enclosed by a plasma membrane. The number of polar filament coils varied between

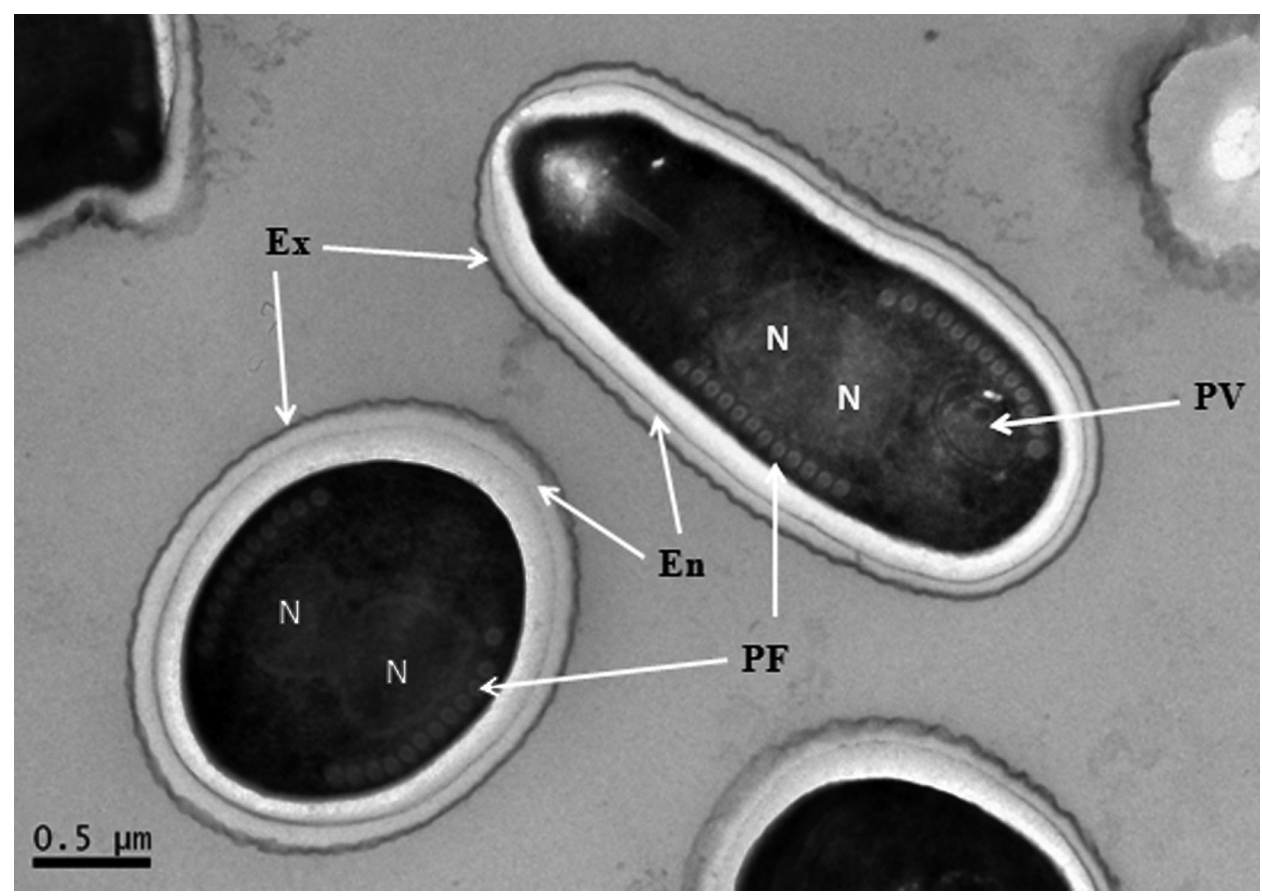

Fig. 1. Electron-micrographs of sections of spores of Nosema sp. HA. Micrograph showing endospore (En), exospores (Ex), nucleus $(\mathrm{N})$, polar filament $(\mathrm{PF})$ and posterior vacuole $(\mathrm{PV})$. 
a

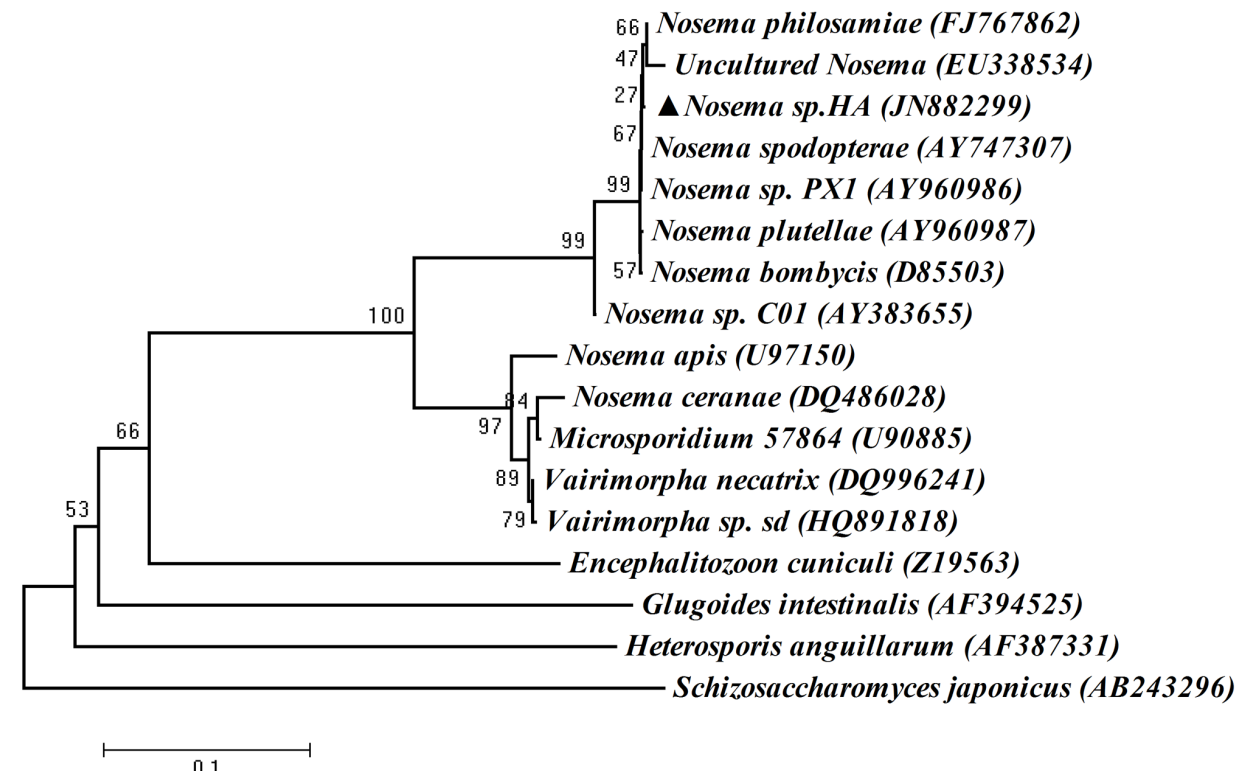

b

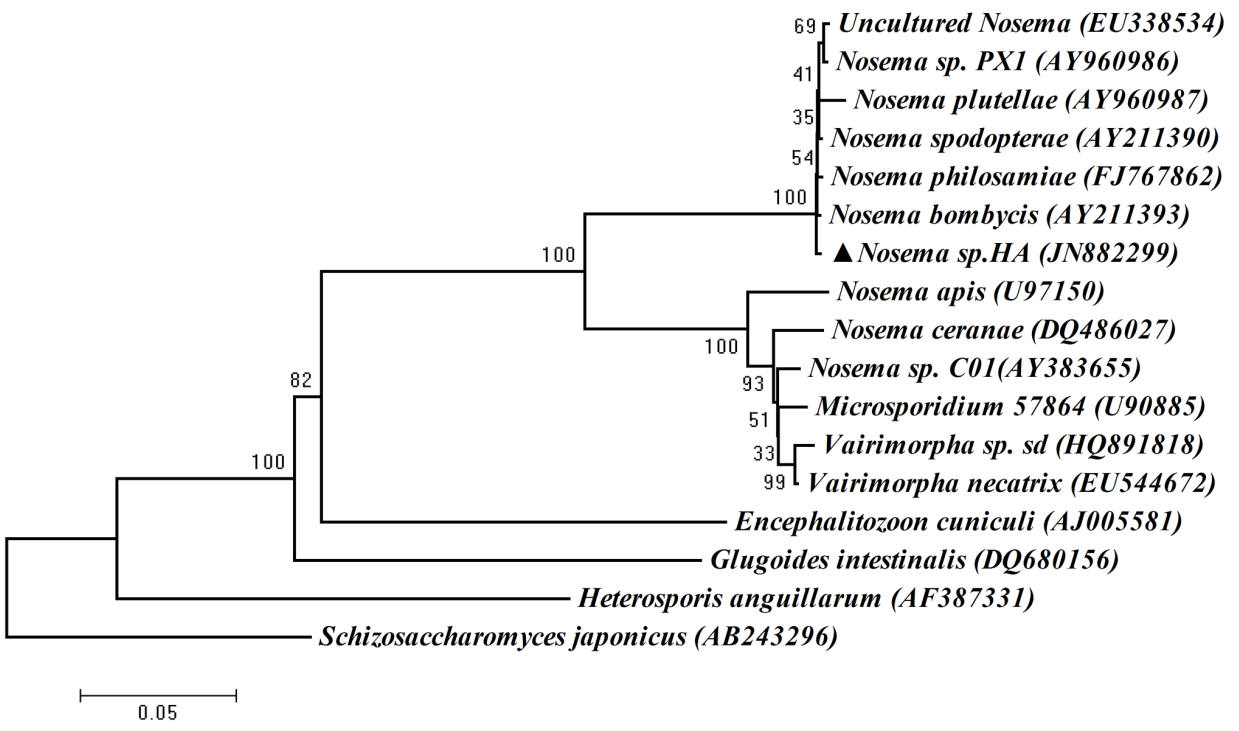

Fig. 2. Phylogenetic analyses of Nosema sp. HA based on the SSU rRNA and LSU rRNA genes; a - a phylogenetic tree based on the SSU rRNA sequences; $\mathbf{b}$ - a phylogenetic tree based on the LSU rRNA sequences. Phylogenetic trees were constructed by using the neighbor joining method. The bootstrap values are indicated at the nodes. The GenBank accession number for each sequence is given adjacent to the corresponding species name. Nosema sp. HA is indicated by triangle ( $\mathbf{\Delta})$.

11 and 13 in one row, and two nuclei were slightly separated from each other. A vacuole with amorphous content was located at the posterior end of the spore (Fig. 1). All the above-mentioned features correspond to the principle characteristics of the genus Nosema (see Larsson 1986).

\section{Tissue infection}

When the tissues are infected with Nosema sp. HA, a large amount of spores in the tissue cells can overflow, or can be observed under the microscope. The heavily infected silkworm larvae showed loss of appetite, growth retardation and other symptoms. The midgut, Malpighian tubules, muscles, fat body, epithelium, silk glands, hemocytes, nerve tissue and gonads were all infected.

\section{Sequence data}

The rRNA complete sequence of Nosema sp. HA contained 4305 base pairs (bp) (GenBank Accession JN882299). The gene arrangement from the 5 ' end was: the large subunit gene (LSU rRNA) with a length of $2492 \mathrm{bp}$, and $\mathrm{G} / \mathrm{C}$ content of $32.1 \%$; the internal transcribed spacer (ITS) with a length of $187 \mathrm{bp}$, and G/C content of $17.7 \%$; the small subunit gene (SSU rRNA) with a length of $1232 \mathrm{bp}$, and G/C content of $34.1 \%$; the intergenic spacer (IGS) with a length of $279 \mathrm{bp}$, and G/C content of $25.8 \%$; and the $5 \mathrm{~S}$ region $(5 \mathrm{~S})$ with a length of $115 \mathrm{bp}$, and $\mathrm{G} / \mathrm{C}$ content of $44.4 \%$. 


\section{Phylogenetic tree constructed from rRNA sequences}

From the phylogenetic tree inferred from the SSU rRNA (Fig. 2a) and LSU rRNA (Fig. 2b) gene sequences, Nosema sp. HA grouped in the same clade with N. bombycis, $N$. philosamiae, $N$. spodopterae, $N$. plutellae, Nosema sp. PX1 and uncultured Nosema. The SSU rRNA gene of Nosema sp. HA shares high sequence identity with N. bombycis $(99.6 \%)$, N. plutellae $(98.5 \%), N$. spodopterae $(99.7 \%)$, Nosema sp. PX1 (99.7\%), N. philosamiae $(99.5 \%)$, uncultured Nosema $(99.0 \%)$ and Nosema sp. C01 (98.1\%) (Table S1). The LSU rRNA gene of the Nosema sp. HA also shares high sequence identity with N. bombycis $(99.5 \%)$, N. plutellae $(98.4 \%)$, N. spodopterae (99.6\%), Nosema sp. PX1 (99.4\%), N. philosamiae (99.4\%) and uncultured Nosema (99.4\%) (Table S2), but shares only $80 \%-83 \%$ identity with Vairimorpha necatrix (Tables S1, S2).

The ITS of Nosema sp. HA shares high sequence identity with that of $N$. bombycis $(93.3 \%), N$. spodopterae $(91.6 \%)$, uncultured Nosema $(88.2 \%)$, N. plutellae $(86.5 \%)$, N. philosamiae (84.8\%), Nosema sp. PX1 $(92.7 \%)$ (Table S3). On the basis of the results of phylogenetic analysis mentioned above, Nosema sp. HA appears to be closely related to Nosema species.

\section{DISCUSSION}

Since the first microsporidium, Nosema bombycis, was described in 1857, many reports of microsporidia have been published (see Fast et al. 2001, Rao et al. 2004, Johny et al. 2006). We have previously isolated a microsporidium from the Hemerophila atrilineata, a pest of mulberry. In our earlier study, Dong et al. (2010) analyzed information from the SSU rRNA gene sequences of this microsporidium and named it tentatively Nosema sp. HA. In order to know more about this microsporidium, we provide data on its morphology, phylogenetics and infected tissues of its host.

As a matter of fact, many of the early classification of microsporidia resulted in the necessary creation of new Nosema species based on spore size, shape, host-parasite relationship and ultrastructure of spores including number of coils of the polar tube (Rao et al. 2004). The spores of Nosema sp. HA are $3.8 \pm 0.4 \mu \mathrm{m} \times 1.9 \pm 0.3$ in size, the nuclei are diplokaryotic and vertically arranged. The number of polar filament coils varied from 11 to 13 in one row. These characters are in accord with those typical of the genus Nosema as currently defined (Larsson 1986).

Besides its pathogenicity in $H$. atrilineata, Nosema sp. HA can infect the silkworm as well. Since $H$. atrilineata is a mulberry pest and only takes mulberry leaves as food, the infected $H$. atrilineata, its faeces and corpses are probably transmission sources of silkworm pebrine disease and cause sericultural losses.

Compared with most microsporidian rRNA regions that are arranged 5'-SSU-ITS-LSU-3' (Zhu et al. 1994,
Gatehouse and Malone 1998, Müller et al. 2000, Tsai et al. 2002, Huang et al. 2007) the SSU rRNA and LSU rRNA of Nosema sp. HA have been transposed as 5'-LSU-ITSSSU-3'. In this study, the organization of the rRNA gene of the Nosema sp. HA was 5'-LSU-ITS-SSU-IGS-5S-3', which is the same as that in $N$. bombycis, $N$. spodopterae, $N$. plutellae, and uncultured Nosema. The transposition to 5'-LSU-ITS-SSU-3' has occurred in several further Nose$m a$ species that belong to the so-called "true" Nosema: Nosema antheraeae, Nosema sp. PX1, Nosema sp. CPP, Nosema sp. CO and Nosema disstriae (Huang et al. 2004, Tsai et al. 2005, 2009, Wang et al. 2006, Ku et al. 2007, Kyei-Poku et al. 2008).

The arrangement of rRNA genes has recently become a useful tool for identification of microsporidia. Tsai et al. (2005) suggested that the reversed arrangement of rRNA genes such as LSU-SSU-5S arrangement may be a specific characteristic suitable for identification of Nosema species (Huang et al. 2004, Tsai et al. 2005, Ironside 2007). However, there are a few exceptions: Refardt and Mouton (2007) and Xu et al. (2011) reported a similar reverse rRNA arrangement of rRNA subunits in Glugoides intestinalis and Endoreticulatus sp., respectively.

The percentage of sequence similarity has proved to be a reliable criterion for scoring taxonomic relationships among microsporidian species (Baker et al. 1994). The SSU rRNA and LSU rRNA genes of Nosema sp. HA share high sequence identity (98.5-99.7\%) with N. bombycis, N. plutellae, N. spodopterae, Nosema sp. PX1, N. philosamiae and uncultured Nosema. Based on genetic characters, we think that Nosema sp. HA is closely related to the members of the "true" Nosema group.

As the SSU rRNA and LSU rRNA genes have highly conservative characteristics, it is difficult to distinguish between Nosema sp. HA and other Nosema species. Tsai et al. (2005) suggested that the microsporidian ITS sequences have good potential as informative molecular markers. The ITS located between SSU rDNA and LSU rDNA varies largely between species and subspecies, and thus can be used for classification and identification. In this study, the ITS of Nosema sp. HA shares sequence identity only $84-93 \%$ with $N$. bombycis, $N$. spodopterae, uncultured Nosema, N. plutellae, N. philosamiae, Nose$m a$ sp. PX1, which is far less than that of the SSU rRNA and LSU rRNA gene sequences.

Based on morphological characters, the reverse arrangement in the rRNA gene subunits, phylogenetic clustering and sequence similarities of SSU rRNA, LSU rRNA and ITS, we conclude that the Nosema sp. HA is distinctly different from the other known Nosema species.

Acknowledgements. This work was supported by the earmarked fund for the China Agriculture Research System. We are grateful to all who provided the means for us to access free software, which we have used and cited in this article. We thank all partners and lab members for kindly help and criticism. 


\section{REFERENCES}

Baker M.D., Vossbrinck C.R., Maddox J.V., Undeen A.H. 1994: Phylogenetic relationships among Vairimorpha and Nosema species (Microspora) based on ribosomal RNA sequence data. J. Invertebr. Pathol. 64: 100-106.

Bhat S.A., Bashir I., Kamili A.S. 2009: Microsporidiosis of silkworm, Bombyx mori L. (Lepidoptera - Bombycidae): a review. Afr. J. Agric. Res. 4: 1519-1523.

Canning E.U., Lom J., Dyková I. 1986: The Microsporidia of Vertebrates. Academic Press, London, 289 pp.

Corradi N., Haag K.L., Pombert J.F., Ebert D., Keeling P.J. 2009: Draft genome sequence of the Daphnia pathogen Octosporea bayeri: insights into the gene content of a large microsporidian genome and a model for host-parasite interactions. Genome Biol. 10: R106.

Dong S.N., Shen Z.Y., Xu L., Zhu F. 2010: Sequence and phylogenetic analysis of SSU rRNA gene of five microsporidia. Curr. Microbiol. 60: 30-37.

Fast N.M., Keeling P.J. 2001: Alpha and beta subunits of pyruvate dehydrogenase E1 from the microsporidian Nosema locustae: mitochondrion-derived carbon metabolism in microsporidia. Mol. Biochem. Parasitol. 117: 201-209.

Franzen C., Muller A. 2001: Microsporidiosis: human diseases and diagnosis. Microbes Infect. 3: 389-400.

Gatehouse H.S., Malone L.A. 1998: The ribosomal RNA gene region of Nosema apis (Microspora): DNA sequence for small and large subunit rRNA genes and evidence of a large tandem repeat unit size. J. Invertebr. Pathol. 71: 97-105.

Huang W.F., Tsai S.J., Lo C.F., Yamane S., Wang C.H. 2004: The novel organization and complete sequence of the ribosomal RNA gene of Nosema bombycis. Fungal Genet. Biol. 41: 473-481.

Hunang W.F., Jiang J.H., Chen Y.W., Wang C.H. 2007: A Nosema ceranae isolate from the honeybee Apis mellifera. Apidologie 38: $30-37$.

IRONSIDE J.E. 2007: Multiple losses of sex within a single genus of Microsporidia. BMC Evol. Biol. 7: e48.

James T.Y., Kauff F., Schoch C.L., Matheny P.B., Hofstetter V., Cox C.J., Celio G., Gueidan C., Fraker E., Miadlikowska J., Lumbsch H.T., Rauhut A., Reeb V., Arnold A.E., Amtoft A., Stajich J.E., Hosaka K., Sung G.H., Johnson D., O'Rourke B., Crockett M., Binder M., Curtis J.M., Slot J.C., Wang Z., Wilson A.W., Schüssler A., Longcore J.E., O'Donnell K., Mozley-Standridge S., Porter D., Letcher P.M., Powell M.J., Taylor J.W., White M.M., Griffith G.W., Davies D.R., Humber R.A., Morton J.B., Sugiyama J., Rossman A.Y., Rogers J.D., Pfister D.H., Hewitt D., Hansen K., Hambleton S., Shoemaker R.A., Kohlmeyer J., Volkmann-Kohlmeyer B., Spotts R.A., Serdani M., Crous P.W., Hughes K.W., Matsuura K., Langer E., Langer G., Untereiner W.A., Lücking R., Büdel B., Geiser D.M., Aptroot A., Diederich P., Schmitt I., Schultz M., Yahr R., Hibbett D.S., Lutzoni F., McLaughlin D.J., Spatafora J.W., Vilgalys R. 2006: Reconstructing the early evolution of Fungi using a six-gene phylogeny. Nature 443: 818-822.

Johny S., Kanginakudru S., Muralirangan M.C., Nagaraju J. 2006: Morphological and molecular characterization of a new microsporidian (Protozoa: Microsporidia) isolated from Spodoptera litura (Fabricius) (Lepidoptera: Noctuidae). Parasitology 132: 803-814.
Ku C.T., Wang C.Y., Tsai, Y.C., Tzeng C.C., Wang C.H. 2007: Phylogenetic analysis of two putative Nosema isolates from cruciferous lepidopteran pests in Taiwan. J. Invertebr. Pathol. 95: 71-76.

Kyei-Poku G.K., Gauthier D., van-Frankenhuyzen K. 2008: Molecular data and phylogeny of Nosema infecting lepidopteran forest defoliators in the genera Choristoneura and Malacosoma. J. Eukaryot. Microbiol. 55: 51-58.

LARSOON R. 1986: Ultrastructure, function, and classification of microsporidia. In: J.O. Corliss and D.J. Patterson (Eds.), Progress in Protistology. Vol. 1. Biopress, Bristol, England, pp. 325-390.

Liu H., Pan G., Li T., Huang W., Luo B., Zhou Z. 2011: Ultrastructure, chromosomal karyotype, and molecular phylogeny of a new isolate of microsporidian Vairimorpha sp. BM (Microsporidia, Nosematidae) from Bombyx mori in China. Parasitol. Res. 110: 205-210.

Müller A., Trammer T., Chioralia G., Seitz H.M., Diehl V., Franzen C. 2000: Ribosomal RNA of Nosema algerae and phylogenetic relationship to other microsporidia. Parasitol. Res. 86: 18-23.

Rao S.N., Muthulakshmi M., Kanginakudru S., Nagaraju J. 2004: Phylogenetic relationships of three new microsporidian isolates from the silkworm, Bombyx mori. J. Invertebr. Pathol. 86: 87-95.

Refardt D., Mouton L. 2007: Reverse arrangement of rRNA subunits in the microsporidium Glugoides intestinalis. J. Eukaryot. Microbiol. 54: 83-85.

Schuld M., Madel G., Schmuck R. 1999: Impact of Vairimorpha sp. (Microsporidia: Burnellidae) on Trichogramma chilonis (Hymenoptera, Trichogrammatidae), a hymenopteran parasitoid of the cabbage moth, Plutella xylostella (Lepidoptera, Yponomeutidae). J. Invertebr. Pathol. 74: 120-126.

Solter L.F., Becnel J.J. 2000: Entomopathogenic microsporidia. In: L.A. Lacey and H. Kaya (Eds.), Field Manual of Techniques for the Evaluation of Entomopathogens. Kluwer Academic Publishers, Dordrecht, The Netherlands, pp. 231-254.

Sprague V. 1977: Systematics of the Microsporidia. Plenum Press, New York, 510 pp.

Tamura K., Dudley J., Nei M., Kumar S. 2007: MEGA4: Molecular Evolutionary Genetics Analysis (MEGA) software version 4.0. Mol. Biol. Evol. 24: 1596-1599.

Tsai S.J., Huang W.F., Wang C.H. 2005: Complete sequence and gene organization of the Nosema spodopterae rRNA gene. J. Eukaryot. Microbiol. 52: 52-54.

Tsai S.J., Kou G.H., Lo C.F., Wang C.H. 2002: Complete sequence and structure of ribosomal RNA gene of Heterosporis anguillarum. Dis. Aquat. Org. 49: 199-206.

Tsai S.J., Lo C.F., Soichi Y., Wang C.H. 2003: The characterization of microsporidian isolates (Nosematidae: Nosema) from five important lepidopteran pests in Taiwan. J. Invertebr. Pathol. 83: 51-59.

Tsai Y.C., Solter L.F., Wang C.Y., Fan H.S., Chang C.C., WANG C.H. 2009: Morphological and molecular studies of a microsporidium (Nosema $\mathrm{sp}$.) isolated from the thee spot grass yellow butterfly, Eurema blanda arsakia (Lepidoptera: Pieridae). J. Invertebr. Pathol. 100: 85-93.

Wang L.L., Chen K.P., Zhang Z., Yao Q., GaO G.T., ZhaO Y. 2006: Phylogenetic analysis of Nosema antheraeae (Mi- 
crosporidia) isolated from Chinese oak silkworm, Antheraea pernyi. J. Eukaryot. Microbiol. 53: 310-313.

Wasson K., Peper R.L. 2000: Mammalian microsporidiosis. Vet. Pathol. 37: 113-128.

Wittner M., Weiss L.M. 1999: The Microsporidia and Microsporidiosis. ASM Press, Washington, D.C., 553 pp.

Xu X., Shen Z., Zhu F., Tao H., Tang X., Xu L. 2011: Phylogenetic characterization of a microsporidium (Endoreticulatus sp. Zhenjiang) isolated from the silkworm, Bombyx mori. Parasitol. Res. 110: 815-819.

Zhu F., Shen Z.Y., Guo X.J., Xu X.F., Tao H.P., Tang X.D., Xu L. 2011: A new isolate of Nosema sp. (Microsporidia, Nose-

Received 12 February 2012 matidae) from Phyllobrotica armata Baly (Coleoptera, Chrysomelidae) from China. J. Invert. Pathol. 106: 339-342.

Zhu F., Shen Z.Y., Xu X.F., Tao H.P., Dong S.N., Tang X.D., XU L. 2010: Phylogenetic analysis of complete rRNA gene sequence of Nosema philosamiae isolated from the lepidopteran Philosamia cynthia ricini. J. Eukaryot. Microbiol. 57: 294-296.

Zhu X., Wittner M., Tanowitz H.B., Cali A., Weiss L.M. 1994: Ribosomal RNA sequences of Enterocytozoon bieneusi, Septata intestinalis and Ameson michaelis: phylogenetic construction and structural correspondence. J. Eukaryot. Microbiol. 41: 204-209.

Accepted 4 May 2012 